\title{
Allelopathic interactions of linoleic acid and nitric oxide increase the competitive ability of Microcystis aeruginosa
}

\author{
Hao Song ${ }^{1}$, Michel Lavoie ${ }^{2}$, Xiaoji $\mathrm{Fan}^{3}$, Hana Tan ${ }^{3}$, Guangfu Liu ${ }^{1}$, Pengfei Xu${ }^{1}$, \\ Zhengwei $\mathrm{Fu}^{3}$, Hans W Paerl ${ }^{4,5}$ and Haifeng Qian ${ }^{1,6}$ \\ ${ }^{1}$ College of Environment, Zhejiang University of Technology, Hangzhou, China; ${ }^{2}$ Quebec-Ocean and Takuvik \\ Joint International Research Unit, Université Laval, Lavel, QC, Canada; ${ }^{3}$ College of Biotechnology and \\ Bioengineering, Zhejiang University of Technology, Hangzhou, China $;{ }^{4}$ Institute of Marine Sciences, \\ University of North Carolina at Chapel Hill, Morehead City, NC, USA; ${ }^{5}$ College of Environment, \\ Hohai University, Nanjing, China and ${ }^{6}$ Xinjiang Key Laboratory of Environmental Pollution and \\ Bioremediation, Chinese Academy of Sciences, Urumqi, China
}

\begin{abstract}
The frequency and intensity of cyanobacterial blooms are increasing worldwide with major societal and economic costs. Interactions between toxic cyanobacteria and eukaryotic algal competitors can affect toxic bloom formation, but the exact mechanisms of interspecies interactions remain unknown. Using metabolomic and proteomic profiling of co-cultures of the toxic cyanobacterium Microcystis aeruginosa with a green alga as well as of microorganisms collected in a Microcystis spp. bloom in Lake Taihu (China), we disentangle novel interspecies allelopathic interactions. We describe an interspecies molecular network in which $M$. aeruginosa inhibits growth of Chlorella vulgaris, a model green algal competitor, via the release of linoleic acid. In addition, we demonstrate how M. aeruginosa takes advantage of the cell signaling compound nitric oxide produced by $C$. vulgaris, which stimulates a positive feedback mechanism of linoleic acid release by $M$. aeruginosa and its toxicity. Our high-throughput system-biology approach highlights the importance of previously unrecognized allelopathic interactions between a broadly distributed toxic cyanobacterial bloom former and one of its algal competitors.
\end{abstract}

The ISME Journal (2017) 11, 1865-1876; doi:10.1038/ismej.2017.45; published online 11 April 2017

\section{Introduction}

The frequency and intensity of toxin-producing cyanobacterial blooms (CBs) are increasing worldwide because of nutrient over-enrichment from human population growth, urbanization, agricultural and industrial expansion and the synergistic effects of global climate change (Paerl, 2009; Paerl and Paul, 2012; Rigosi et al., 2014, 2015). This threatens the sustainability of freshwater ecosystems by negatively affecting water and habitat quality, drinking water supplies and food webs (Carmichael, 2001; Paerl, 2008). In the United States of America, eutrophication and resultant CBs have been estimated to cost from ten to hundreds of billions of dollars per year (Dodds et al., 2008; Hamilton et al., 2014). In China, numerous large, shallow lakes such as Lake Taihu and Lake Chaohu have suffered serious CBs from late

Correspondence: H Qian, College of Environment, Zhejiang university of Technology, No 18, Chaowang Road, Hangzhou, Zhejiang 310032, China.

E-mail: hfqian@zjut.edu.cn

Received 25 October 2016; revised 15 January 2017; accepted 16 February 2017; published online 11 April 2017 spring to autumn since the 1990s (Duan et al., 2009; Jiang et al., 2014). Clearly, CBs are a growing environmental, ecological and economic concern worldwide.

Freshwater CBs are promoted by increasing loads of nitrogen $(\mathrm{N})$ and phosphorus (P), light, rising temperatures and altered precipitation patterns accompanying climate change (Paerl and Paul, 2012; Wang et al., 2012). However, the biotic factors triggering toxic $\mathrm{CBs}$ are still poorly understood. Allelopathy, the production and release of biomolecules to inhibit or kill competitor species, can alter plankton community composition (Uronen et al., 2007). The study of the roles and mechanisms of allelopathic interactions between algal competitors and cyanobacteria in bloom and toxicity dynamics are of increasing interest (Paerl et al., 2001; Leão et al., 2009; Beversdorf et al., 2013). Even though pre-conditioned media of cyanobacteria cultures have been shown to inhibit the growth of algal competitors (Borowitzka, 2016), the underlying mechanisms remain largely unknown and the importance of allelopathic interactions in the establishment of toxic CBs is yet to be demonstrated. 
A range of secondary metabolites (for example, anatoxin, microcystin and microcarbonin A) have been isolated that can be toxic to biota (from zooplankton to humans) and negatively affect the growth of algal competitors; however, the complex network of interactions at the molecular levels has remained elusive (Borowitzka, 2016). One widely distributed toxic cyanobacterial genus that forms increasingly problematic blooms is Microcystis. Microcystis is known to inhibit photosynthesis in the dinoflagellate Peridinium gatunense via production of microcarbonin A (Sukenik et al., 2002), and can also inhibit the growth of several green algal species with a as yet unknown mechanism (Ma et al., 2015; Bittencourt-Oliveira et al., 2015).

Here, we disentangled the complex network of interactions mediating the negative allelopathic effect(s) of Microcystis aeruginosa on one of its competitors, the green alga, Chlorella vulgaris-two dominant species often co-occurring in blooms (Cai et al., 2014). We cultivated both species separated by a dialysis membrane in the laboratory and analyzed the effects on each other at the proteome and metabolome levels as well as on the biochemistry of the signaling molecules involved. We further explored the presence of cyanobacterial allelopathic molecules in Lake Taihu (China) and monitored changes in the microbial community structure during a Microcystis bloom.

\section{Materials and methods}

Algal culturing techniques

Axenic cultures of $C$. vulgaris (strain FACHB-24) and M. aeruginosa (strain FACHB-905) were obtained from the Institute of Hydrobiology (Chinese Academy of Sciences, Wuhan, China). These algae were grown in sterilized BG-11 liquid medium and incubated in an environmental chamber at $25 \pm 0.5^{\circ} \mathrm{C}$ under cool white fluorescent lights $\left(46 \mu \mathrm{mol} \mathrm{m}{ }^{-2} \mathrm{~s}^{-1}, 12 \mathrm{~h}\right.$ light $/ 12 \mathrm{~h}$ dark). The cell density of cultures was monitored by spectrophotometry daily, and 6 and $12 \mathrm{~h}$ time points were added on the first day. For the cell density measurements, we used a regression equation relating cell density $\left(y \times 10^{5} \mathrm{ml}^{-1}\right)$, as determined by a hemacytometer, and the optical density at $685 \mathrm{~nm}$ or OD685 $(x)$, that is, $y=162.1 x+1.4\left(R^{2}=99.34 \%\right)$ for $C$. vulgaris (Qian et al., 2013), and $y=34.1 x+0.7\left(R^{2}=99.17 \%\right)$ for M. aeruginosa (Qian et al., 2010). All manipulations followed sterile techniques under a laminar flow hood.

\section{Co-culture experimental design}

A co-culture device was used to investigate allelopathic interactions between $M$. aeruginosa and C. vulgaris (Paul et al., 2009; Poulson-Ellestad et al., 2014). Permeable dialysis cellulose membrane tubing (pore size $12 \mathrm{kDa}, 76 \mathrm{~mm} \times 49 \mathrm{~mm}$; SigmaAldrich, St Louis, MO, USA) was used to separate the cultures of both species in co-culturing experiments (Poulson-Ellestad et al., 2014). Dialysis membrane tubing was cut into sections of $\sim 35 \mathrm{~cm}$, soaked overnight in deionized water and then rinsed eight times with deionized water according to the manufacturer's recommendations. One end of the dialysis membrane tubing was closed by tying a knot, autoclaved at $121{ }^{\circ} \mathrm{C}$ for $15 \mathrm{~min}$, and the other end of the dialysis bag was suspended with a sterilized wire, which was tied to a glass rod. This device allowed for transport of allelopathic compounds from M. aeruginosa through the dialysis membrane over the course of the experiment, but cell contact between species was prevented (Paul et al., 2009).

The sterilized dialysis system was kept under laminar flow until use. Preparation of algal cultures first involved transferring $200 \mathrm{ml}$ of C. vulgaris cultures into a sterilized $1000 \mathrm{ml}$ glass beaker. Then, a dialysis bag filled with $200 \mathrm{ml}$ of fresh medium was inoculated with $M$. aeruginosa cultures via the Teflon tubing, and submerged into glass beakers containing the $C$. vulgaris cultures. The coculturing device was agitated at 90 rotations per min on a laboratory shaker. Reverse co-cultures with $C$. vulgaris inside the dialysis bag and $M$. aeruginosa in the glass flask were also performed, and no differences in growth rates were measured in either of the co-culturing systems used. Control cultures were also prepared similarly, except that only one species was cultivated in both the dialysis bag and the beaker. Different initial cell densities of M. aeruginosa were tested (from $7.5 \times 10^{4}$ to $3 \times 10^{5}$ cells per ml), but the initial cell density of the C. vulgaris cultures remain constant to $1.8 \times 10^{6}$ cells per ml, resulting in ratios of initial cell density of C. vulgaris to $M$. aeruginosa of 6-24. Cell densities of $M$. aeruginosa were representative of cell density measured using a hemocytometer in Lake Taihu water samples for that species (from $1 \times 10^{4}$ cells per $\mathrm{ml}$ in oligotrophic situations and reaching $3 \times 10^{5}$ cells per $\mathrm{ml}$ at the bloom peak). The initial cell density chosen for $C$. vulgaris was within twofold of cell densities measured in Lake Taihu.

After 1-4 days of co-culture, the cell yield was measured and the relative growth inhibition of $C$. vulgaris was calculated with the following equation: $100 \times$ OD control-OD treatment/OD control (OD, optical density). OD control and OD treatment refer to the optical density at $685 \mathrm{~nm}$ of the control monocultures and of the treatment (co-cultures). Total nitrogen and total phosphorus were also measured at the start and at the end of the 4-day experiments. All subsequent measurements in algal cultures described below were done using co-cultures with a ratio of initial cell density of $C$. vulgaris to $M$. aeruginosa of 12:1 as well as with monocultures.

\section{Cellular and subcellular structure analysis}

The observation of the $C$. vulgaris cell surface microstructure was performed using a ZEISS SUPRA 55 high-performance field emission scanning 
electron microscope (Carl Zeiss Meditec AG, Jena, Germany). The C. vulgaris cells cultured alone or co-cultured with $M$. aeruginosa for 4 days (C. vulgaris to $M$. aeruginosa initial cell density ratio of 12:1) were harvested by centrifugation at 7000 r.p.m. and fixed with $2.5 \%$ glutaraldehyde, $0.4 \%$ paraformaldehyde and $0.1 \mathrm{M}$ sodium phosphate buffer $(\mathrm{pH}$ $7.2)$ for $24 \mathrm{~h}$. The fixed algae were dehydrated in absolute alcohol and dried with hexamethyldisilizane, and the dry samples were coated with a $0.5-1 \mathrm{~cm}^{2}$ area of conductive adhesive. Images of C. vulgaris cell surface were processed with the Image-Pro Plus software (Media Cybernetics, Silver Spring, MD, USA).

Subcellular structures were visualized using transmission electron microscopy. Algal samples from the control and co-culture were fixed with $1.0 \% \mathrm{OsO}_{4}$ and embedded in epoxy resin. The samples were then cut into ultra-thin sections $(70-90 \mathrm{~nm})$ using a Reichert Ultracut S ultramicrotome and stained sequentially with uranyl acetate and lead citrate. A JEM-1230 transmission electron microscope (JEOL Ltd., Tokyo, Japan) was used to observe the ultrastructure of $C$. vulgaris.

Measurement of chlorophyll fluorescence parameters MINI-PAM-II (Walz, Effectich, Germany) was used to measure $F_{\mathrm{v}} / F_{\mathrm{m}}$ ratio (maximum photosynthetic efficiency of photosystem II), relative electron transport rates and photochemical quenching (qP) of $C$. vulgaris cultured alone or co-cultured with M. aeruginosa for 4 days (ratio of $C$. vulgaris to M. aeruginosa initial cell density of 12:1). The algae were placed in a dark environment for $15 \mathrm{~min}$ before the measurements of chlorophyll fluorescence parameters.

\section{Metabolomic analyses}

Approximately $0.3 \mathrm{~g}$ of $C$. vulgaris or $M$. aeruginosa was collected by centrifugation after 4 days of coculture or of monocultures (control) for the analysis of the metabolome of each species. Algal cells were dissolved with $8 \mathrm{ml}$ solvent (including methanol: water $=4: 1 \mathrm{v} / \mathrm{v} ; 400 \mu \mathrm{l}$ chloroform; $20 \mu \mathrm{l}$ internal standard) and sonicated for $6 \mathrm{~min}$ (power $=950 \mathrm{~W}$, frequency $=20 \mathrm{kHz}$ ) on ice using a Ultrasonic cell crusher SCIENTZ-II D. Algal homogenates were then centrifuged at 12000 r.p.m. for $15 \mathrm{~min}$ and supernatants were collected for further purification. In parallel, C. vulgaris cultures (grown in co-cultures with $M$. aeruginosa or in monocultures) were filtered on $0.7-\mu \mathrm{m}$ Whatman $\mathrm{GF} / \mathrm{F}$ fiberglass filters at $0.1 \mathrm{MPa}$ and the filtrates were collected for metabolomic analysis of the culture medium. All supernatants were then freeze-dried, dissolved in $500 \mu \mathrm{l}$ of $80 \%$ methanol and derivatized with $80 \mu \mathrm{l} \mathrm{N}$, O-Bis (trimethylsilyl) trifluoroacetamide $\left(15 \mathrm{mg} \mathrm{ml}^{-1}\right)$ including $1 \%$ chlorotrimethylsilane. Each $2 \mu \mathrm{l}$ aliquot of the derivatized solution (algae homogenate or culture medium) was injected in a splitless mode into the 7890B-5977A GC/MSD GC-MS system (Agilent Technologies, Palo Alto, CA, USA). Metabolite separation was carried out on a non-polar DB-5 capillary column $(30 \mathrm{~m} \times 250 \mu \mathrm{m}$ I.D., J\&W Scientific, Folsom, CA, USA), with high-purity helium as the carrier gas at a constant flow rate of $1.0 \mathrm{ml} \mathrm{min}{ }^{-1}$. The GC oven temperature program was as follows: beginning at $90^{\circ} \mathrm{C}$, followed by a $10^{\circ} \mathrm{C}$ $\min ^{-1}$ ramp up to $180^{\circ} \mathrm{C}$, a $5^{\circ} \mathrm{Cmin}^{-1}$ ramp up to $240^{\circ} \mathrm{C}$, a $25^{\circ} \mathrm{C} \mathrm{min}^{-1}$ ramp up to $290^{\circ} \mathrm{C}$ and a final 11 min maintenance at $290^{\circ} \mathrm{C}$. The electron impact ion source was held at $260{ }^{\circ} \mathrm{C}$ with a filament bias of - $70 \mathrm{~V}$. Full-scan mode $(\mathrm{m} / \mathrm{z}$ 50-450) was used, with an acquisition rate of 37.132 spectrum per $s$ in the MS setting. All the MS data were finally analyzed using the ChromaTOF software ( $\mathrm{v}$ 4.34, LECO, St Joseph, MI, USA).

\section{Proteomic analyses}

After 4 days of co-culture or in monocultures (control), $\sim 0.3 \mathrm{~g}$ of algal fresh weight per sample of $C$. vulgaris or $M$. aeruginosa was collected by centrifugation, extracted and digested with trypsin for analysis of the proteome of each species by 8-plex isobaric tags for relative and absolute quantitation (iTRAQ). Equal amounts of iTRAQ-labeled (AB Science, Framingham, MA, USA) peptides from each group were mixed and resolved into 15 fractions by high-performance liquid chromatography followed by Q Exactive plus hybrid quadrupole-Orbitrap mass spectrometry (Thermo Fisher Scientific, Waltham, MA, USA). The resulting mass spectrometry/mass spectrometry data were processed using the Mascot search engine (v.2.3.0) and searched against a Uniprot Chlamydomonas database for $C$. vulgaris or a $M$. aeruginosa protein database for $M$. aeruginosa using MaxQuant (v1.0.13.13) with a false discovery rate of $1 \%$ and peptide ion score set to $\geqslant 20$. Mass error was set to 10 p.p.m. for precursor ions and $0.02 \mathrm{Da}$ for fragment ions.

Functions were attributed to the quantified proteins using gene ontology annotation, Kyoto Encyclopedia of Genes and Genomes pathway analysis, functional enrichment and secondary structure analysis. Two replicates with tag swapping were conducted for each of the two biological replicates.

Detection of intracellular reactive oxygen species, nitric oxide content, superoxide dismutase activity, pyruvate, acetyl-CoA and linoleic acid cell contents

The amount of reactive oxygen species (ROS) per cell produced by $C$. vulgaris when co-cultured or not (control) with $M$. aeruginosa for $6 \mathrm{~h}$ to 4 days were measured using the cell-permeant probe $2^{\prime}, 7^{\prime}$ dichlorodihydrofluorescein diacetate following the manufacturer's instructions (Beyotime Institute of Biotechnology, Haimen, China). Quantification of nitric oxide (NO) in $C$. vulgaris cells was detected with the fluorescent dye 4-amino-5-methylamino- 
$2^{\prime}, 7^{\prime}$-difluorofluorescein diacetate (Beyotime Institute of Biotechnology, Nantong, China). Fifty milliliters of algal cultures were collected by centrifugation at 7000 r.p.m., and were used to measure superoxide dismutase (SOD) activity as well as pyruvate and acetyl-CoA contents (Qian et al., 2008). SOD activity was measured using a SOD kit (Dojindo Laboratories, Kumamoto, Japan). The pyruvate and acetyl-CoA cell content was determined using commercially available pyruvate (Nanjing Jiancheng Bioengineering Institute, Jiangsu, China) and acetyl-CoA kits (Jiangsu, Comin, Suzhou, China) following the instructions provided by the manufacturer. Total linoleic acid (LA) concentrations at each station of Lake Taihu as well as in cocultures of $M$. aeruginosa and $C$. vulgaris (4 days, treatment 12:1) and in control monocultures were analyzed by gas chromatography (Work et al., 2010). Further information on ROS, NO and LA analyses is provided in Supplementary Materials and Methods.

Effects of exogenous NO on the growth and LA synthesis in monocultures and co-cultures

We evaluated the effects of different NO concentrations on cell growth and LA synthesis in co-cultures of both species or in monocultures of $M$. aeruginosa over $96 \mathrm{~h}$. The NO concentrations were adjusted by adding different concentrations $(0.05,0.1,0.25$ and $0.5 \mu \mathrm{M})$ of sodium nitroprussate (SNP, Sigma Company, St Louis, MO, USA), a well-known NO donor or of 2-phenyl4,4,5,5-tetramethyl-imidazoline-1-oxyl-3-oxide (c-PTIO, Sigma Company; 0.05, 0.1, 0.25 and $0.5 \mu \mathrm{M}$ ), a NO scavenger, in the culture medium. We also tested the influence of c-PTIO $(0.05,0.1,0.25,0.5,2$ and $4 \mu \mathrm{M})$ addition on the growth of $C$. vulgaris in monocultures and on NO concentrations in these cultures. The effect of co-cultures of both species (initial cell density ratio of $C$. vulgaris to $M$. aeruginosa of 12:1) for 4 days on NO concentrations was also studied. The $\mathrm{pH}$ of each culture was adjusted to the same initial value before the experiments.

\section{Effects of different putative allelochemical molecules} on C. vulgaris growth and NO production

We tested the effects of different potential allelopathic molecules (LA, methyl palmitoleate, microcystin, mono (2-ethylhexyl-phtalate); $1 \mu \mathrm{g} \mathrm{l}^{-1}$ ), which were previously identified as candidates mediating the allelopathic interactions of $M$. aeruginosa on $C$. vulgaris, on the growth of $C$. vulgaris in monocultures. The effects of LA addition (20$60 \mathrm{~g} \mathrm{l}^{-1} \mathrm{LA}$; the most potent allelochemical) on the growth of $C$. vulgaris in monocultures and NO concentrations were also determined.

Field sampling

Lake Taihu is located in the Yangtze Basin, bordering Shanghai, Jiangsu, and Zhejiang provinces in the southeastern part of China $\left(30^{\circ} 55^{\prime} 40^{\prime \prime}-31^{\circ} 32^{\prime} 58^{\prime \prime} \mathrm{N}\right.$; $119^{\circ} 52^{\prime} 32^{\prime \prime}-120^{\circ} 36^{\prime} 10^{\prime \prime}$ E). To compare the difference between aquatic microbial communities in the region of algal blooms and non-algal blooms, eight sampling transects encompassing the northern half of Lake Taihu were conducted during 10-11 August 2015, when a CB was present. Further information on eight sampling transects and microbial diversity analyses are provided in Supplementary Materials and Methods.

\section{Statistical analyses}

Statistical significance among data for the biochemical and physiological measurements was tested by analysis of variance followed by the Dunnett's post hoc test using the StatView 5.0 program (Statistical Analysis Systems Institute, Cary, NC, USA). When the probability $(P)$ was less than 0.05 , the means were considered significantly different. The metabolomic data sets were imported into the SIMCA-P+ 14.0 software package (Umetrics, Umeá, Sweden). All analyses were performed in triplicate unless otherwise stated. All data are presented in the tables and figures as mean \pm s.e.m.

\section{Results and Discussion}

M. aeruginosa inhibits $C$. vulgaris growth

C. vulgaris growth was significantly inhibited by M. aeruginosa. After 1-4 days of co-culture, the cell yield of $C$. vulgaris decreased by $9-24 \%$, using initial cell number ratio of $C$. vulgaris to $M$. aeruginosa varying from 24:1 to 6:11 (Figure 1a). As the inhibitory effect of $M$. aeruginosa on the growth of C. vulgaris did not increase significantly when the initial cell number ratio decreased from 12:1 to 6:1, we chose the treatment with an initial cell number ratio of $C$. vulgaris to $M$. aeruginosa of 12:1 for all subsequent analyses involving co-cultures. In contrast, the growth of $M$. aeruginosa did not change significantly when co-cultured with $C$. vulgaris (data not shown). Over the 4-day experiment, total dissolved $\mathrm{P}$ and $\mathrm{N}$ concentrations remained constant over time and did not change significantly among treatments (co-cultures with a 12:1 C. vulgaris to $M$. aeruginosa initial cell density ratio and control monocultures of C. vulgaris; Supplementary Figure S1). Both species grew exponentially over the exposure time in the co-cultures or monocultures. This suggested that the inhibitory effect of $M$. aeruginosa on the growth of $C$. vulgaris was mediated by allelopathy rather than exploitation competition. Moreover, the mean $\mathrm{pH}$ was similar in the co-cultures and in monocultures of $C$. vulgaris ( $\mathrm{pH}$ increasing from 7.1 to 7.6 from day 1 to day 4), indicating that $M$. aeruginosa allelopathy was not related to changes in the $\mathrm{pH}$ of the medium. This is in accordance with the reported allelopathic effects of $M$. aeruginosa on several other species of green algae (Bittencourt-Oliveira et al., 2015; Ma et al., 
a

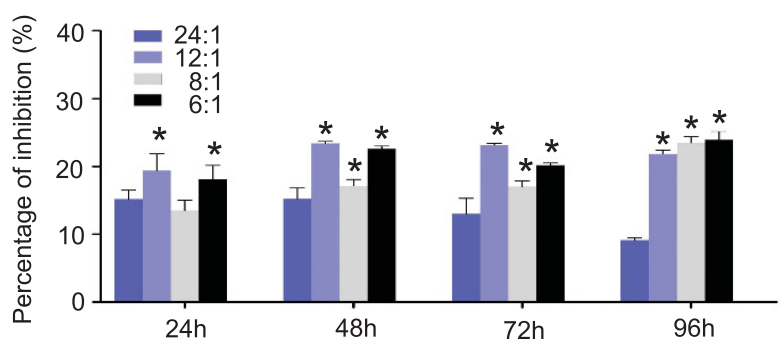

C
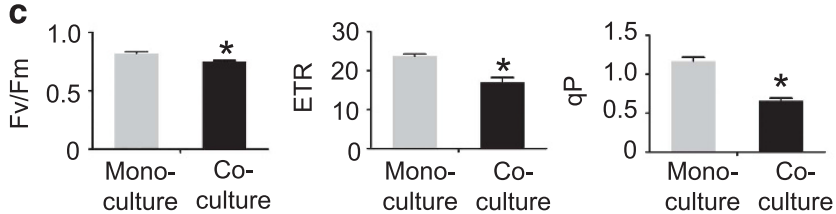

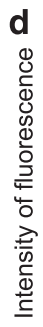

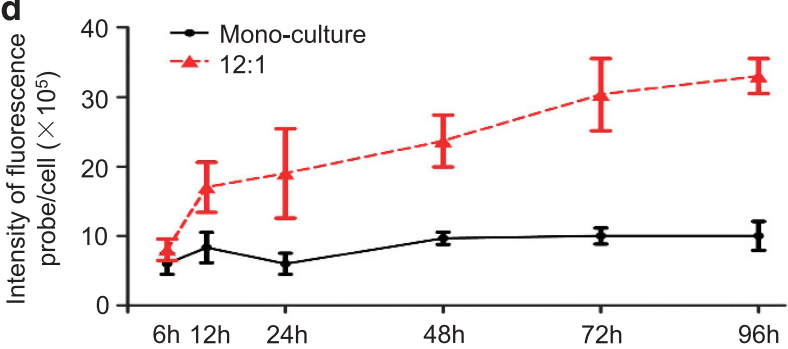

e

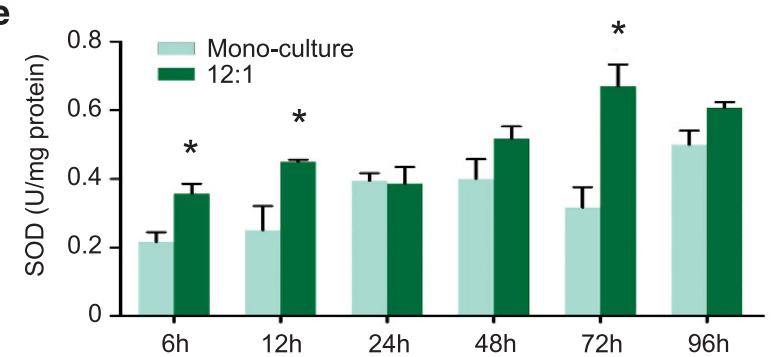

b

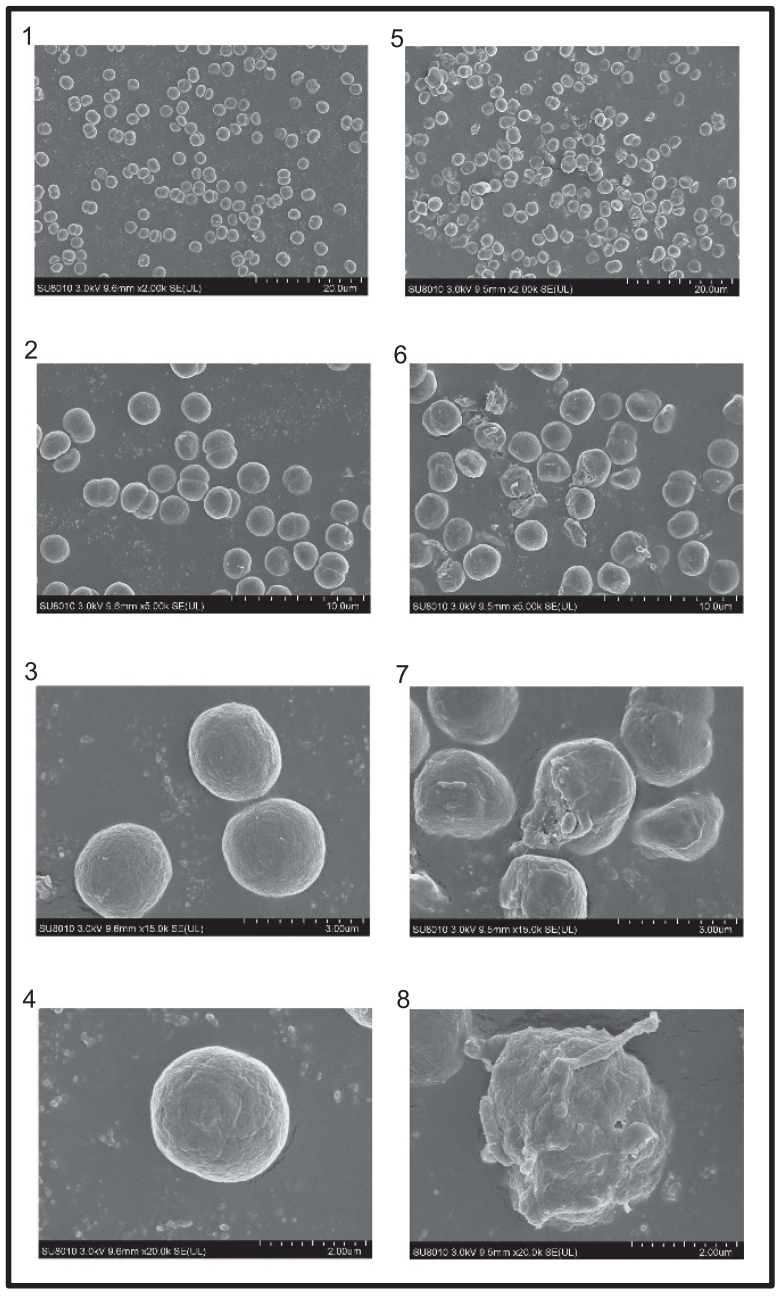

Figure 1 Effect of Microcystis aeruginosa on Chlorella vulgaris physiology. (a) Effects of M. aeruginosa allelopathy on the cell yield of $C$. vulgaris over 4 days with different initial cell density ratios of $C$. vulgaris to M. aeruginosa. Inhibition of cell yield (\%) of $C$. vulgaris is calculated in co-cultures of M. aeruginosa and $C$. vulgaris compared to control monocultures of $C$. vulgaris in the dialysis system without the presence of $M$. aeruginosa. (b) The effect of $M$. aeruginosa allelopathy on the cell surface of $C$. vulgaris as visualized by scanning electron microscope (SEM). C. vulgaris monoculture (left images) and co-culture (right images). (c) Effects of M. aeruginosa allelopathy on photosynthetic efficiency $\left(F_{\mathrm{v}} / F_{\mathrm{m}}\right)$, photochemical quenching (qP) and relative electron transport rate (ETR) of $C$. vulgaris. (d) Effects of M. aeruginosa allelopathy on ROS content of $C$. vulgaris. ROS content is expressed in relative units of fluorescence intensity per cell. (f) Effects of $M$. aeruginosa allelopathy on SOD activity of $C$. vulgaris. In $\mathbf{b}-\mathbf{f}$, an initial cell density ratio of $C$. vulgaris to $M$. aeruginosa of 12:1 was used in the co-culture and algae were cultivated for 4 days. Monoculture represents treatments with $C$. vulgaris grown in the dialysis system without the presence of $M$. aeruginosa. Asterisks represent statistically significant differences relative to control $\left({ }^{\star} P<0.05\right.$, analysis of variance (ANOVA)). Values are mean \pm s.e.m. $(n=4)$.

2015). Scanning electron microscope analyses also indicated that the abundance of dividing cells of C. vulgaris in the treatment (co-culture) group decreased by twofold relative to the control group (C. vulgaris in monoculture; Figure 1b). Approximately $20 \%$ of total cells were dividing in the control group, while $\sim 10 \%$ of cells in the treatment (coculture) group were dividing (Figure $1 \mathrm{~b}$ ), indicating that $M$. aeruginosa inhibited cellular division processes in C. vulgaris.

Proteomic and metabolomic response of algae

Co-cultures affected the synthesis of several proteins and metabolites in both species (Tables 1,2 and
Supplementary Table S1). We detected and quantified 41 differentially expressed proteins (18 underexpressed and 23 overexpressed) in C. vulgaris in response to the presence of $M$. aeruginosa (Table 1), whereas there were 25 differentially expressed proteins in $M$. aeruginosa (9 underexpressed and 16 overexpressed) when co-cultured with $C$. vulgaris (Supplementary Table S1). On the basis of our proteomics and metabolomics analyses, M. aeruginosa allelopathy has an impact on multiple metabolic pathways involved in energy generation and metabolism, including glycolysis, carbon fixation and fatty-acid biosynthesis. M. aeruginosa allelopathy significantly inhibited the photosynthetic capability of $C$. vulgaris, as evidenced by the decreased 
Table 1 The effect of $M$. aeruginosa allelopathy on the proteome of $C$. vulgaris

\begin{tabular}{|c|c|c|c|}
\hline Up or down expression & Protein names and categories & Ratio & P-value \\
\hline \multicolumn{4}{|l|}{ Photosynthesis } \\
\hline$\triangle$ & Cytochrome b6-f complex subunit 4 & 0.7 & $3.44 \mathrm{E}-03$ \\
\hline $\boldsymbol{\nabla}$ & Photosystem I iron-sulfur center & 0.4 & $6.82 \mathrm{E}-09$ \\
\hline$\nabla$ & Light-independent protochlorophyllidereductase subunit $\mathrm{N}$ & 0.7 & $2.04 \mathrm{E}-02$ \\
\hline $\boldsymbol{\nabla}$ & Photosystem II protein D1 & 0.5 & $6.51 \mathrm{E}-04$ \\
\hline $\boldsymbol{\nabla}$ & Photosystem II reaction center protein $\mathrm{H}$ & 0.7 & $1.04 \mathrm{E}-04$ \\
\hline $\boldsymbol{\nabla}$ & Photosystem I reaction center subunit IX & 0.6 & $2.4 \mathrm{E}-02$ \\
\hline $\boldsymbol{\nabla}$ & Photosystem I P700 chlorophyll a apoprotein A & 0.2 & $2.28 \mathrm{E}-04$ \\
\hline$\nabla$ & Ribulose bisphosphate carboxylase large chain & 0.3 & $1.50 \mathrm{E}-02$ \\
\hline $\boldsymbol{\nabla}$ & Ribulose bisphosphate carboxylase small chain & 0.4 & $2.27 \mathrm{E}-03$ \\
\hline $\boldsymbol{\nabla}$ & Ferredoxin-NADP reductase & 0.7 & $7.88 \mathrm{E}-05$ \\
\hline$\triangle$ & Cytochrome $f$ & 1.3 & $2.97 \mathrm{E}-05$ \\
\hline \multicolumn{4}{|l|}{ Membrane transporters } \\
\hline$\nabla$ & 1-acyl-sn-glycerol-3-phosphate acyltransferase & 0.5 & $4.23 \mathrm{E}-02$ \\
\hline$\triangle$ & 'Cytochrome b-c1 complex subunit Rieske, mitochondrial' & 1.4 & $3.80 \mathrm{E}-02$ \\
\hline \multicolumn{4}{|l|}{ Protein homeostasis } \\
\hline$\nabla$ & '30S ribosomal protein S8, chloroplastic’ & 0.3 & $3.88 \mathrm{E}-02$ \\
\hline$\triangle$ & $40 \mathrm{~S}$ ribosomal protein $\mathrm{S} 4$ & 1.4 & $2.24 \mathrm{E}-07$ \\
\hline$\triangle$ & $40 \mathrm{~S}$ ribosomal protein $\mathrm{S} 6$ & 1.4 & $5.95 \mathrm{E}-03$ \\
\hline$\triangle$ & Ribosomal protein S7 & 1.4 & $6.56 \mathrm{E}-03$ \\
\hline$\triangle$ & 40 S ribosomal protein $\mathrm{S} 27$ & 1.5 & $7.57 \mathrm{E}-03$ \\
\hline$\triangle$ & $40 S$ ribosomal protein $\mathrm{S} 8$ & 1.4 & $3.03 \mathrm{E}-03$ \\
\hline$\triangle$ & $60 S$ ribosomal protein L13 & 1.4 & $1.97 \mathrm{E}-05$ \\
\hline$\triangle$ & $40 \mathrm{~S}$ ribosomal protein $\mathrm{S} 18$ & 1.6 & $4.41 \mathrm{E}-05$ \\
\hline$\triangle$ & Peptidyl-prolylcis-trans isomerase (fragment) & 1.5 & $1.06 \mathrm{E}-02$ \\
\hline \multicolumn{4}{|l|}{ Energy } \\
\hline$\nabla$ & Kinesin-like protein & 0.7 & $3.47 \mathrm{E}-03$ \\
\hline$\triangle$ & Glucose-6-phosphate 1-dehydrogenase & 1.5 & $2.18 \mathrm{E}-02$ \\
\hline$\triangle$ & ATP synthase F0 subunit beta & 1.6 & $1.25 \mathrm{E}-04$ \\
\hline$\triangle$ & Glyceraldehyde-3-phosphate dehydrogenase (fragment) & 1.3 & $2.14 \mathrm{E}-02$ \\
\hline$\triangle$ & Fructose-bisphosphate aldolase & 1.7 & $4.92 \mathrm{E}-04$ \\
\hline$\triangle$ & Glycerol-3-phosphate dehydrogenase [NAD(+)] & 1.4 & $1.21 \mathrm{E}-03$ \\
\hline \multicolumn{4}{|c|}{ The uptake and transportation of nitrogen } \\
\hline$\nabla$ & Nitrate transporter NTR & 0.4 & $2.90 \mathrm{E}-02$ \\
\hline$\triangle$ & Nitrate reductase & 1.6 & $4.77 \mathrm{E}-02$ \\
\hline$\triangle$ & Ferredoxin-nitrite reductase & 1.4 & $2.85 \mathrm{E}-03$ \\
\hline \multicolumn{4}{|l|}{ Stress and defense } \\
\hline$\triangle$ & Glutaredoxin & 1.4 & $8.78 \mathrm{E}-06$ \\
\hline$\triangle$ & Cysteine synthase & 1.6 & $2.24 \mathrm{E}-03$ \\
\hline \multicolumn{4}{|l|}{ Signal transduction } \\
\hline$\triangle$ & Putative nitric oxide synthase & 1.5 & $4.47 \mathrm{E}-02$ \\
\hline \multicolumn{4}{|c|}{ Stability and repair of DNA structure } \\
\hline$\nabla$ & Histone H2B & 0.4 & $3.29 \mathrm{E}-02$ \\
\hline$\nabla$ & Histone $\mathrm{H} 4$ & 0.5 & $8.67 \mathrm{E}-05$ \\
\hline $\boldsymbol{\nabla}$ & Heat shock protein 90 & 0.6 & $6.41 \mathrm{E}-03$ \\
\hline$\nabla$ & GrpE protein homolog (fragment) & 0.5 & $1.04 \mathrm{E}-02$ \\
\hline \multicolumn{4}{|c|}{ Nucleoside metabolic process } \\
\hline$\triangle$ & Adenylosuccinatelyase & 1.5 & $9.78 \mathrm{E}-07$ \\
\hline \multicolumn{4}{|l|}{ Fatty-acid metabolism } \\
\hline$\triangle$ & Acyl-coenzyme A synthase & 1.4 & $2.65 \mathrm{E}-07$ \\
\hline$\triangle$ & 3-Oxoacyl-[acyl-carrier-protein] synthase & 1.3 & $3.31 \mathrm{E}-03$ \\
\hline
\end{tabular}

Differentially expressed proteins that were significantly over $(\triangle)$ and under $(\boldsymbol{\nabla})$ expressed by $>1.2$ and $<0.83$, respectively, in $C$. vulgaris exposed to $M$. aeruginosa allelopathy relative to protein expression in C. vulgaris monocultures are shown and categorized in metabolic pathways and cellular functions.

expression of 10 proteins involved in electron transfer in the chloroplast (for example, cytochrome b6-f complex subunit 4: 0.7-fold, photosystem I ironsulfur center: 0.4 -fold of the control, see Table 1) as well as a threefold decrease in the expression of ribulose bisphosphate carboxylase (Rubisco) largechain protein. The negative allelopathic effect of $M$. aeruginosa on $C$. vulgaris photosynthesis also 
Table 2 Cellular M. aeruginosa metabolites whose concentrations increased $(\triangle)$ or decreased $(\boldsymbol{\nabla})$ when grown in co-cultures with C. vulgaris

\begin{tabular}{|c|c|c|c|c|}
\hline Up or down expression & Candidate metabolite & Biological subcategory & Fold change & P-value \\
\hline$\triangle$ & Methyl palmitoleate & Fatty-acid biosynthesis & 7.7 & $1.67 \mathrm{E}-08$ \\
\hline$\triangle$ & Linoleic acid & Fatty-acid biosynthesis & 5.1 & $2.07 \mathrm{E}-03$ \\
\hline$\triangle$ & Mono(2-ethylhexyl)phthalate & Fatty-acid biosynthesis & 5.2 & $3.07 \mathrm{E}-03$ \\
\hline $\boldsymbol{\nabla}$ & Oxalic acid & Tricarboxylic acid cycle/osmoregulation & 0.5 & $1.21 \mathrm{E}-08$ \\
\hline $\boldsymbol{\nabla}$ & Xanthine & Purine metabolism & 0.6 & $2.11 \mathrm{E}-03$ \\
\hline $\boldsymbol{\nabla}$ & Phenylacetic acid & Phenylalanine metabolism & 0.5 & $2.05 \mathrm{E}-08$ \\
\hline $\boldsymbol{\nabla}$ & 3-Hexenedioic acid & Organic acid metabolism & 0.7 & $1.99 \mathrm{E}-05$ \\
\hline $\boldsymbol{\nabla}$ & Pyrrole-2-carboxylic acid & Organic acid metabolism & 0.8 & $5.12 \mathrm{E}-04$ \\
\hline $\boldsymbol{\nabla}$ & Cytidine-monophosphated egrprod & Pyrimidine metabolism & 0.7 & $3.34 \mathrm{E}-07$ \\
\hline $\boldsymbol{\nabla}$ & 3-hydroxy-L-proline & Arginine and proline & 0.5 & $4.47 \mathrm{E}-05$ \\
\hline $\boldsymbol{\nabla}$ & Erythrose & Metabolism glycolysis & 0.8 & $2.17 \mathrm{E}-05$ \\
\hline $\boldsymbol{\nabla}$ & Digitoxose & Glycolysis & 0.6 & $2.35 \mathrm{E}-06$ \\
\hline
\end{tabular}

Metabolites that were significantly over $(\triangle)$ and under $(\boldsymbol{\nabla})$ expressed in $M$. aeruginosa grown in co-cultures with $C$. vulgaris relative to control monocultures of $M$. aeruginosa are shown and categorized in metabolic pathways and cellular functions.

translated into a significant decrease of $F_{\mathrm{v}} / F_{\mathrm{m}}$, electron transport rate and $\mathrm{qP}$ by $8.7 \%, 28.3 \%$ and $43.6 \%$ relative to the control after 4 days of co-culture, respectively (Figure 1c), which are indicative of a decrease of photosynthetic efficiency of photosystem II (Qian et al., 2010, 2011; Kiran Kumar Reddy et al., 2014). A significant 3.3-fold decrease in glucose cell content, a 1.3- to 1.7-fold increase in the cell content of the two key glycolysis enzymes (glyceraldehyde-3-phosphate dehydrogenase, fructose-bisphosphate aldolase, ATP synthase F0 subunit beta; Table 1), as well as an increase in ATP synthase Fo subunit beta cell content were observed.

In concert, these results suggest that the enzymes involved in glucose oxidation and energy production (via the glycolytic pathway and the tricarboxylic acid cycle) were enhanced in $C$. vulgaris, potentially boosting NADPH synthesis. Moreover, we measured a 1.4-fold increase in ribulose-5-phosphate (an intermediate in the pentose phosphate pathway) concentration in $C$. vulgaris exposed to $M$. aeruginosa allelopathy as well as a 1.5 -fold increase in the abundance of one key enzyme of the pentose phosphate pathway (that is, glucose-6-phosphate 1dehydrogenase). This likely compensated for the decrease in photosynthetically produced NADPH (Kletzien et al., 1994), which is the main reducing potential utilized for the generation of Asc and reduced glutathione (Noctor et al., 1998) under stress conditions (Gill and Tuteja, 2010; Zhao et al., 2015). The expression of enzymes involved in $\beta$-oxidation (acyl-coenzyme A synthase) and synthesis (3-oxoacyl-[acyl-carrier-protein] synthase) of fatty acids also significantly increased in C. vulgaris by 1.4- and 1.3fold relative to control, respectively, in response to M. aeruginosa allelopathy. Although pyruvate cell content did not change significantly, acetyl-CoA (precursor of fatty acids) amount per cell increased significantly by 1.3-fold (Supplementary Figure S2).

Our results suggest that the synthesis of the biochemical machinery associated with both fatty-acid synthesis and oxidation was stimulated in $C$. vulgaris exposed to $M$. aeruginosa. The perturbations that impacted $C$. vulgaris lead to a 1.9-fold increase of lignoceric acid production as well as to a decrease in LA and beta-mannosylglycerate by $0.7-$ and 0.5 -fold, respectively (Supplementary Table S2). The induction of fatty-acid synthesis combined with the differential expression of a range of osmoprotective compounds (sarcosine, proline, DL anabasine, allo-inositol and 2-hydroxyvaleric acid; Supplementary Table S2) is suggestive of membrane-restructuring processes taking place in response to possible changes in membrane permeability.

Underexpression of the photosynthetic machinery combined with overexpression of enzymes involved in fatty-acid $\beta$-oxidation suggest that $C$. vulgaris became carbon-limited as recently demonstrated in the diatom Thalassiosira pseudonana exposed to the allelopathic molecules released by the toxic dinoflagellate Karenia brevis (Poulson-Ellestad et al., 2014).

The significant decrease in expression of the proteins histone $\mathrm{H} 4$ and histone $\mathrm{H} 2 \mathrm{~B}$ (involved in nucleosome assembly and chromosomal segregation in the G2 phase) by 2- and 2.5-fold in C. vulgaris exposed to $M$. aeruginosa allelopathy relative to control monocultures is consistent with the SEM results showing cell division inhibition in $C$. vulgaris (Figure 1b). M. aeruginosa also induced atrophy of the $C$. vulgaris nucleus based on transmission electron microscopy analysis (Supplementary Figure S3).

\section{C. vulgaris signaling compounds}

ROS production in C. vulgaris increased by $3.3-$ fold in co-cultures with M. aeruginosa (Figure 1d), even though the expression of two antioxidant enzymes increased by 1.4- and 1.6-fold and SOD activity significantly increased between $6 \mathrm{~h}$ and 3 days of exposure (Figure 1e). In parallel, we measured a significant 2.5-fold decrease in nitrate transporter expression (Table 1). Hence, it is possible that the recently discovered ROS-induced decrease in $\mathrm{N}$ 
assimilation in the diatom Phaeodactylum tricornutum (Rosenwasser et al., 2014) could also occur in $C$. vulgaris exposed to $M$. aeruginosa.

In contrast, expression of proteins involved in NO production in C. vulgaris increased (for example, nitrate reductase: 1.6-fold; putative NO synthase (putative NOS): 1.5-fold; see Table 1). These proteins are involved in reshuffling and recycling of internal nitrogen stores and the synthesis of NO, which is increasingly recognized as a key cell-signaling molecule in algae (Yordanova et al., 2010). Furthermore, our metabolomics data indicate that the cell content of sarcosine (a metabolite in the putative pathway leading to NO production via NOS) markedly increased by 10.7-fold (Supplementary Table S2). Such a high NO production, which is further measured and discussed later in the manuscript, could play several signaling roles. These include programmed cell death as demonstrated in Chlamydomonas reinhardtii (Yordanova et al., 2010), influence on cell development and division as demonstrated in higher plants (Ferrer and Ros Barcel, 1999) and could also influence M. aeruginosa allelopathy.
C. vulgaris affects $\mathrm{M}$. aeruginosa metabolism In the presence of $C$. vulgaris, $M$. aeruginosa increased the expression of proteins involved in the synthesis of fatty acids by 1.5- to 2.3-fold (longchain fatty-acid CoA ligase, acyl-carrier protein, acyl-carrier protein), energy generation by 1.3- to 1.5-fold (for example, citrate synthase, ATP synthase subunits), photosynthesis by 1.4- to 1.6-fold (Psb28, Ycf3) and amino acid by 1.7-fold (threonine synthase; Supplementary Table S1). Since NO produced by $C$. vulgaris is the main signaling molecule affecting $M$. aeruginosa allelopathy and LA production (see below), it is also likely that NO affects energy generation via tricarboxylic acid cycle and photosynthesis. NO is indeed known to have a positive effect on plant development and differentiation (Tan et al., 2008; Fröhlich and Durner, 2011).

\section{Interspecies network of interactions}

At the metabolomics level, cell content of several fatty acids and metabolites particularly increased in $M$. aeruginosa co-cultured with $C$. vulgaris: methyl palmitoleate (7.7-fold), LA (5.1-fold), mono (2-
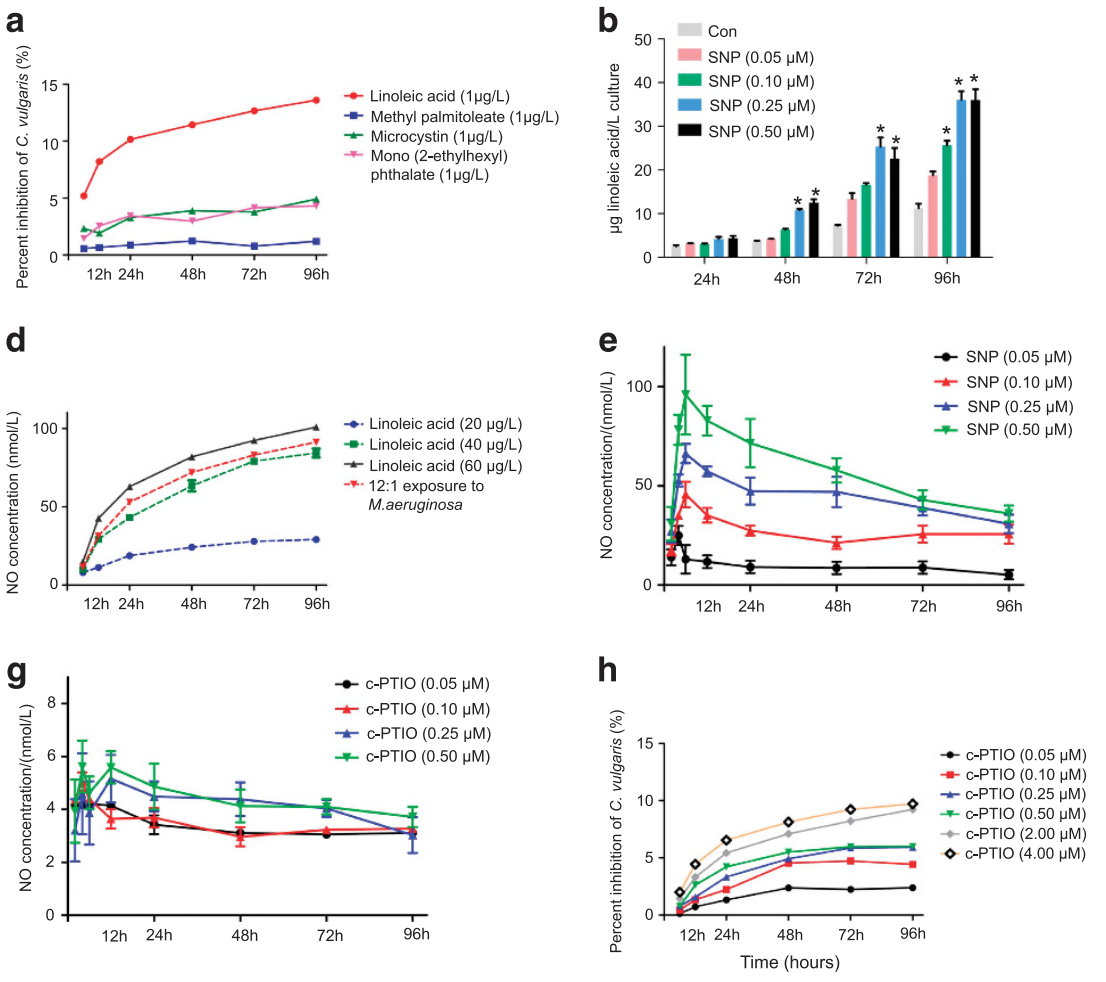

Figure 2 The effect of multiple exogenous metabolite additions on $C$. vulgaris. (a) Cell yield inhibition (\%) of $C$. vulgaris in monoculture exposed to $1 \mathrm{~g} \mathrm{l}^{-1}$ linoleic acid (LA), methyl palmitoleate, microcystin and mono (2-ethylhexyl) phthalate for different periods of time. (b) The effect of SNP (NO donor) on LA production $\left(\mu \mathrm{g} \mathrm{l}^{-1}\right.$ ) in monocultures of M. aeruginosa. (c) The effect of c-PTIO (NO scavenger) on LA $\left(\mu \mathrm{l}^{-1}\right.$ ) production in $M$. aeruginosa cultivated in co-cultures. (d) NO concentrations (nmol $\mathrm{l}^{-1}$ ) in $C$. vulgaris with monoculture and coculture exposed to 20-60 $\mathrm{gg} \mathrm{l}^{-1} \mathrm{LA}$ for different periods of time. (e) The effect of SNP on NO concentrations (nmol $1^{-1}$ ) in monocultures of $M$. aeruginosa. (f) The effect of SNP on cell yield of $M$. aeruginosa in monocultures. (g) The effect of c-PTIO on the cell yield of $C$. vulgaris cultivated in co-cultures. (h) Cell yield inhibition (\%) of C. vulgaris alone exposed to $0.05-4 \mu \mathrm{M} \mathrm{c}-\mathrm{PTIO}$ for different periods of time. (i) The effect of c-PTIO on the cell yield of $C$. vulgaris cultivated in co-cultures. Controls in a, h are $C$. vulgaris monocultures grown in the BG-11 medium without addition of metabolites or $\mathrm{c}-\mathrm{PTIO}$. Asterisks represent statistically significant differences relative to control $\left({ }^{*} P<0.05\right.$, ANOVA). Values are mean \pm s.e.m. $(n=3)$. 
ethylhexyl) phthalate (5.2-fold; Table 2) and microcystin (3.2-fold; independently analyzed by highperformance liquid chromatography). Furthermore, the concentration of methyl palmitoleate and LA in co-culture medium also increased by $8.7-$ and 9.4-fold relative to the control, respectively (Supplementary Table S3). To explore the allelopathic potential of these molecules, we added them individually to $C$. vulgaris monocultures. The cell yield of $C$. vulgaris after 4 days of exposure to $1 \mu \mathrm{gl}^{-1}$ of LA, methyl palmitoleate, microcystin and mono (2-ethylhexyl) phthalate was inhibited by $13.6 \%, 1.2 \%, 4.9 \%$ and $4.3 \%$, respectively, relative to untreated controls (Figure 2a), suggesting that LA could be an important allelopathic molecule produced by $M$. aeruginosa. The LA (Figures $2 \mathrm{~b}$ and c, see control bars) and microcystin concentrations we used were representative of those measured in cocultures. The fatty-acid LA has been previously shown to inhibit growth, as chlorophyll production of phytoplankton including green algae, although at high concentrations ( $>\mathrm{mg} \mathrm{l}^{-1}$; Ikawa et al., 1996; Chiang et al., 2004; Wu et al., 2006). However, our results suggest that trace LA concentrations can be an effective allelopathic molecule in short-term (4 days) growth experiments of $C$. vulgaris. The toxicity targets and action mechanisms of fatty acids remain poorly understood in phytoplankton and other microorganisms (Desbois and Smith, 2010). LA may adsorb on or penetrate into the cell and then induce metabolic perturbations in $C$. vulgaris.

Analyses of LA production by M. aeruginosa in the presence or absence of NO (Figures $2 b$ and c) also indicate that $M$. aeruginosa-induced NO production in $C$. vulgaris stimulates LA production by $M$. aeruginosa and enhances the negative allelopathic interaction with $M$. aeruginosa. Indeed, we measured LA concentration in cultures with $M$. aeruginosa alone (Figure $2 \mathrm{~b}$ ) and found that $M$. aeruginosa produced little LA (see control bars). However, in the presence of NO, LA concentration was induced (Figure 2b). Moreover, the LA concentration was higher in $M$. aeruginosa grown in cocultures (Figure 2c, see control bars) than in $M$. aeruginosa monocultures alone (Figure 2b, see control bars). Quantitative analysis of NO production in laboratory algal cultures with/without addition of LA (Figures 2c and d) indicates that LA, which is produced by $M$. aeruginosa according to our metabolomic study, is the key molecule stimulating NO production by $C$. vulgaris. Indeed, under our experimental conditions, we observed that the addition of 20 to $60 \mu \mathrm{gl}^{-1} \mathrm{LA}$ (close to those measured in $M$. aeruginosa grown in co-cultures, see Figure 2c control bars after 4 days) in cultures of $C$. vulgaris alone increased NO production to $84.2 \mathrm{~nm}$ after a

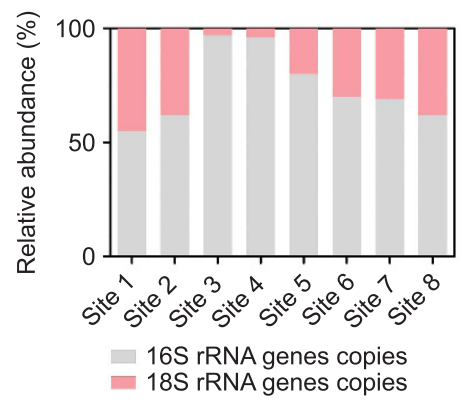

c

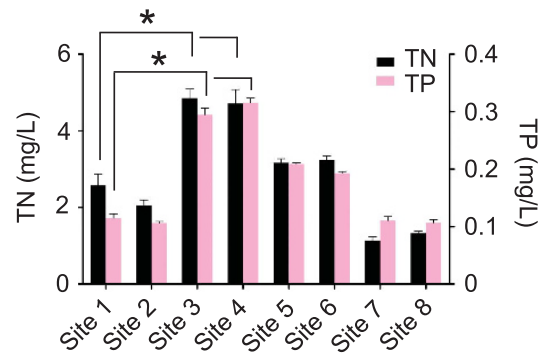

b

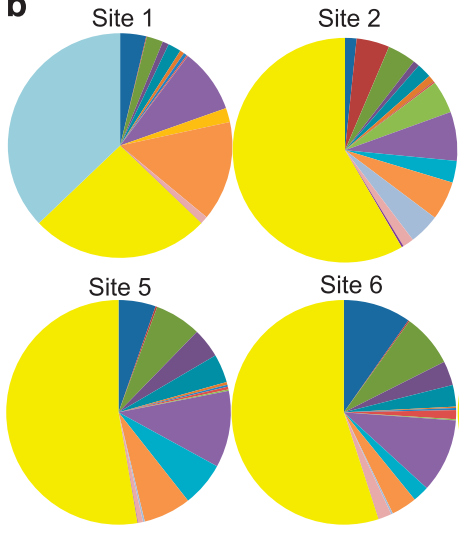

d

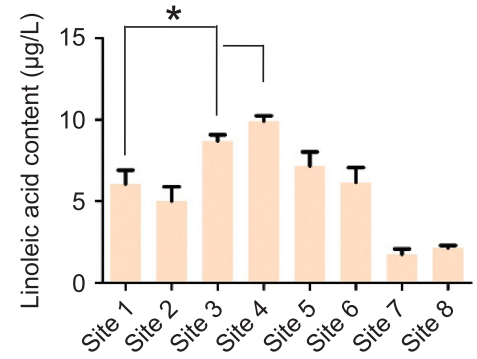

Site 4
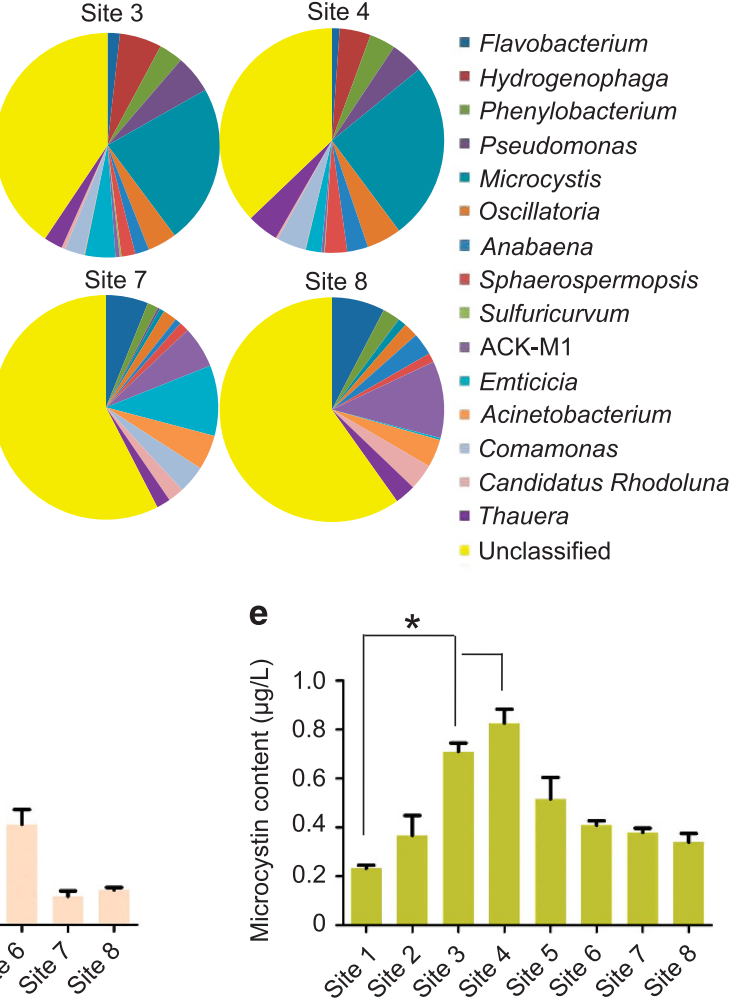

Figure 3 Aquatic microbial community profile analyses. (a) The mean relative abundance of 16S rRNA genes and 18S rRNA genes copies in surface samples collected in Lake Taihu. (b) Genera-level taxonomic distribution of the major aquatic microorganism community profile. Total nitrogen (TN) and total phosphorus (TP;(c)), LA (d) and particulate microcystin concentration (e) in surface water of Lake Taihu over the sampling period (mean of the eight stations). Asterisks represent statistically significant differences between treatments $\left({ }^{*} P<0.05\right.$, ANOVA). Data are means \pm s.e.m. $(n=4$ per site $)$. 
4 days of exposure, which was close to the NO concentration produced by $C$. vulgaris after 4 days in co-cultures (91.2 nм NO; Figure 2d), indicating that LA is a key allelopathic molecule inducing NO release from $C$. vulgaris.

To further demonstrate that NO produced by $C$. vulgaris plays an essential role in stimulating $M$. aeruginosa allelopathy, we added SNP (NO donor) and c-PTIO (NO scavenger) to adjust the NO concentration in the medium of cultures of $M$. aeruginosa alone or in co-cultures. We found that NO concentration in $M$. aeruginosa increased in a concentration-dependent manner with SNP (Figure 2e). NO concentration in $M$. aeruginosa increased significantly after $6 \mathrm{~h}$ of exposure, and reached about $66.3 \mathrm{~nm}$ in the presence of $0.25 \mu \mathrm{M}$ SNP (Figure 2e), which was similar to the NO concentration ( $\sim 52.9 \mathrm{~nm})$ measured in C. vulgaris, which was cultivated in co-cultures for $24 \mathrm{~h}$ (initial cell number ratio of $C$. vulgaris to $M$. aeruginosa= 12:1; Figure 2d). Experiments carried out in the presence of $0.25 \mu \mathrm{M}$ SNP in monocultures of $M$. aeruginosa revealed that this NO concentration did not affect $M$. aeruginosa growth significantly (Figure 2f). At the same time, LA levels reached $36.1 \mathrm{\mu g} \mathrm{l}^{-1}$ in the $M$. aeruginosa monoculture (Figure 2b), which represents a 3.2-fold increase relative to that of the control (without added SNP) after 4 days of exposure (Figure 2b). This increase was close to that found in our metabolomics analysis, where LA concentration in $M$. aeruginosa increased by 5.1 -fold relative to the control after 4 days of co-culture (Table 2). This indicated that NO produced by $C$. vulgaris induced LA excretion from $M$. aeruginosa. The addition of c-PTIO into coculture medium scavenged $C$. vulgaris-produced NO completely (Figure 2g). At the same time, the total LA concentration in the C. vulgaris compartment of the co-culture system decreased by fivefold after 4 days of exposure to $0.5 \mu \mathrm{M}$ c-PTIO relative to the c-PTIO-free control without addition of c-PTIO (Figure 2c).

Taken together, our results clearly showed that NO could be an important signaling molecule regulating the production of secondary metabolites (such as LA) in $M$. aeruginosa, indicating that $M$. aeruginosa allelopathy to $C$. vulgaris can be enhanced in the presence of $C$. vulgaris. Furthermore, NO scavenging by c-PTIO treatment $(\geqslant 0.05 \mu \mathrm{M})$ could maintain optimal C. vulgaris growth alone (Figure $2 \mathrm{~h}$ ) or in co-culture experiments (Figure 2i), highlighting the fact that additional NO-scavenging processes could inhibit or suppress the negative allelopathic interactions between $M$. aeruginosa and $C$. vulgaris and that the strength of $M$. aeruginosa allelopathy should be maximized when both species are close to each other such as in aggregates or algal colonies.

\section{Cyanobacteria allelopathy in nature}

The absolute abundance of cyanobacterial 16S rRNA was much higher at stations 3 and 4 than in other stations of Lake Taihu (Supplementary Table S4). The absolute abundance of eukaryotic organisms (18S rRNA), however, increased much less than that of prokaryotic organisms at stations 3-4 (Supplementary Table S5). We also found that the relative abundance of eukaryotic algae decreased significantly in parallel with the CBs (Figure 3a). The operational taxonomic unit data revealed that $\sim 70 \%$ of aquatic microorganisms belonged to cyanobacteria at stations 3 and 4 , while cyanobacteria at other sampling sites occupied only $40 \%$ of the aquatic microbial community. At stations 3 and 4 the

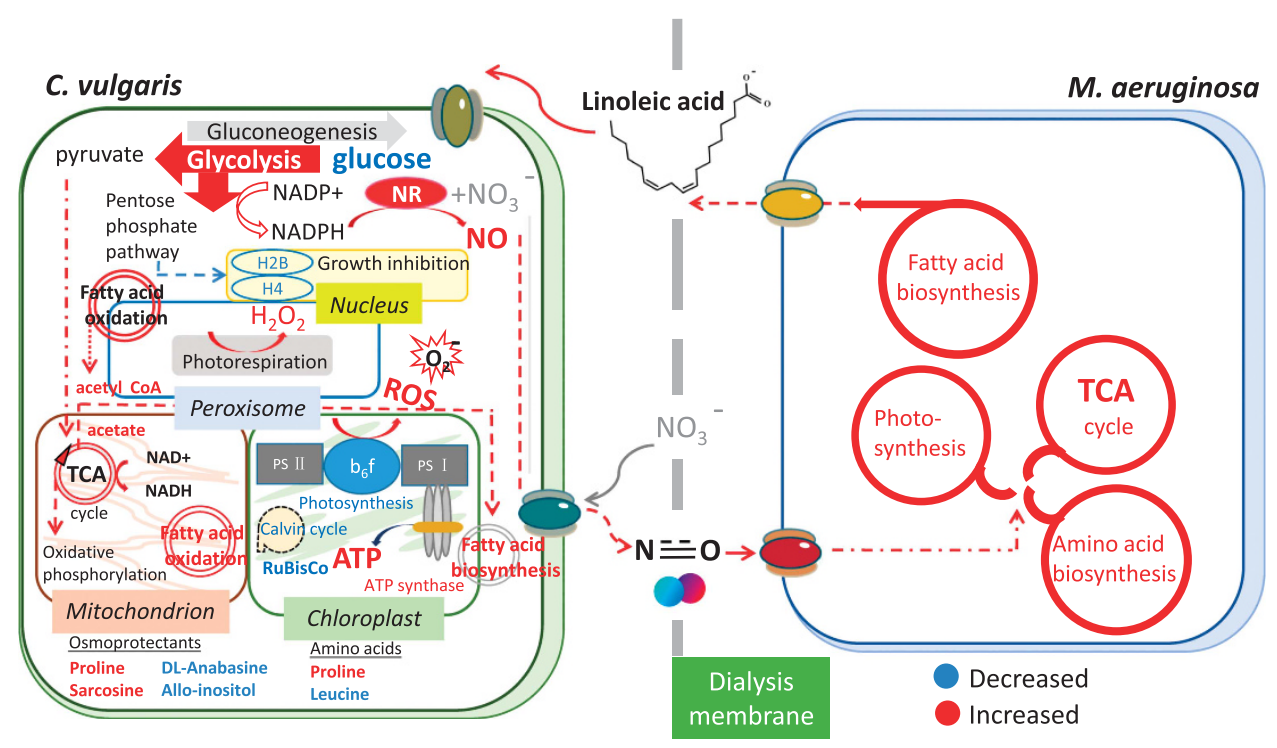

Figure 4 Conceptual model of the allelopathic interactions between $M$. aeruginosa and $C$. vulgaris at the cellular level. The network of cellular pathways, enzymes and metabolites in $C$. vulgaris due to $M$. aeruginosa allelopathy is derived from biochemical, metabolomics and proteomics analyses. The biochemical pathways (arrows) and metabolites in blue and red are increased and decreased, respectively. 
percentage of Microcystis increased by approximately eightfold relative to other sites (Figure 3b). Although these differences in microbial abundance among lake stations could be related, at least partly, by an increase in nutrient ( $\mathrm{N}$ and $\mathrm{P}$ ) concentrations (Figure 3c), we found that Microcystis allelopathy could also shape the structure of the microbial community. Indeed, the concentration of the main allelopathic compound of $M$. aeruginosa, LA was approximately fivefold higher in Microcystis spp.-rich stations of Lake Taihu (8.5$10.4 \mu \mathrm{g} \mathrm{LA} / \mathrm{L})$ than at other stations, in which no Microcystis blooms occurred ( $2 \mu \mathrm{gl}^{-1}$; Figure 3d). Microcystin concentrations were only between 0.2 and $0.8 \mu g l^{-1}$ among the eight stations, indicating that it was not the main allelopathic compound in Lake Taihu (Figure 3e), which is in line with the findings of Babica et al. (2007).

\section{Conclusions}

Our high-throughput system biochemical and metabolomic approach unraveled for the first time the intricate allelopathic interactions between a bloom-forming toxic cyanobacterial species and an algal competitor. We disentangled the network of interactions explaining the negative allelopathic effect of $M$. aeruginosa on $C$. vulgaris. $M$. aeruginosa inhibits the growth of C. vulgaris mainly via the release of LA and also takes advantage of NO, a cell-signaling compound produced by $C$. vulgaris (as schematized in Figure 4), which stimulated a positive feedback mechanism of LA release by $M$. aeruginosa as well as its inhibitory effect. Our results highlight the important and previously unrecognized interspecies allelopathic interactions involved in the development and persistence of toxic $M$. aeruginosa blooms in freshwater ecosystems.

\section{Conflict of Interest}

The authors declare no conflict of interest.

\section{Acknowledgements}

This work was financially supported by the Natural Science Foundation of China (21277127, 21577128), Zhejiang Provincial Natural Science Foundation of China (LR14B070001), Program for Changjiang Scholars and Innovative Research Team in University (IRT13096), and the US National Science Foundation (INSPIRE 1230543, and Dimensions of Biodiversity 1240851).

\section{References}

Babica P, Hilscherová K, Bartová K, Bláha L, Marsálek B. (2007). Effects of dissolved microcystins on growth of planktonic photoautotrophs. Phycologia 46: 137-142.

Beversdorf LJ, Miller TR, McMahon KD. (2013). The role of nitrogen fixation in cyanobacterial bloom toxicity in a temperate, eutrophic lake. PLOS ONE 8: e56103.
Bittencourt-Oliveira MDC, Chia MA, Oliveira HSBD, Araújo MKC, Molica RJR, Dias CTS. (2015). Allelopathic interactions between microcystin-producing and non-microcystin-producing cyanobacteria and green microalgae: implications for microcystins production. J Appl Phycol 27: 275-284.

Borowitzka MA. (2016). Chemically-mediated interactions in microalgae. In: Borowitzka MA, Beardall J, Raven AJ (eds). The Physiology of Microalgae. Springer: UK, pp 321-357.

Cai H, Jiang H, Krumholz LR, Yang Z. (2014). Bacterial community composition of size-fractioned aggregates within the phycosphere of cyanobacterial blooms in a eutrophic freshwater lake. PLoS ONE 9: e102879.

Carmichael WW. (2001). Health effects of toxin producing cyanobacteria: 'the cyanoHABs'. Hum Ecol Risk Assess 7: 1393-1407.

Chiang IZ, Huang WY, Wu JT. (2004). Allelochemicals of Botryococcus braunii (Chlorophyceae). J Phycol 40: 474-480.

Desbois AP, Smith VJ. (2010). Antibacterial free fatty acids: activities, mechanisms of action and biotechnological potential. Appl Microbiol Biotechnol 85: 1629-1642.

Dodds WK, Bouska WW, Eitzmann JL, Pilger TJ, Pitts KL, Riley AJ et al. (2008). Eutrophication of US freshwaters: analysis of potential economic damages. Environ Sci Technol 43: 12-19.

Duan HT, Ma RH, Xu XF, Kong FX, Zhang SX, Kong WJ et al. (2009). Two decade reconstruction of algal blooms in China's lake Taihu. Environ Sci Technol 43: 3522-3528.

Ferrer MA, Ros Barcel ÓA. (1999). Differential effects of nitric oxide on peroxidase and $\mathrm{H}_{2} \mathrm{O}_{2}$ production by the xylem of Zinnia elegans. Plant Cell Environ 22: 891-897.

Fröhlich A, Durner J. (2011). The hunt for plant nitric oxide synthase (NOS): is one really needed? Plant Sci 181: 401-404.

Gill SS, Tuteja N. (2010). Reactive oxygen species and antioxidant machinery in abiotic stress tolerance in crop plants. Plant Physiol Biochem 48: 909-930.

Hamilton DP, Wood SA, Dietrich DR, Puddick J. (2014). Costs of harmful blooms of freshwater cyanobacteria. In: Sharma NV, Rai AK, Stal LJ (eds). Cyanobacteria: an Economic Perspective. John Wiley \& Sons: New York, pp 247-256.

Ikawa M, Haney JF, Sasner JJ. (1996). Inhibition of Chlorella growth by the lipids of cyanobacterium Microcystis aeruginosa. Hydrobiologia 331: 167-170.

Jiang YJ, He W, Liu WX, Qin N, Ouyang HL, Wang QM et al. (2014). The seasonal and spatial variations of phytoplankton community and their correlation with environmental factors in a large eutrophic Chinese lake (lake Chaohu). Ecol Indic 40: 58-67.

Kiran Kumar Reddy G, Nancharaiah YV, Venugopalan VP. (2014). Biodegradation of dibutylphosphite by Sphingobium sp. AMGD5 isolated from aerobic granular biomass. Int Biodeterior Biodegrad 91: 60-65.

Kletzien RF, Harris PKW, Foellmi LA. (1994). Glucose-6phosphate-dehydrogenase-a housekeeping enzyme subject to tissue-specific regulation by hormones, nutrients, and oxidant stress. Fed Am Soc Exp Biol J 8: 8174-8181.

Leão PN, Vasconcelos TSD, Vasconcelos VM. (2009). Allelopathy in freshwater cyanobacteria. Crit Rev Microbiol 35: 271-282.

Ma ZL, Fang TX, Thring RW, Li YB, Yu HG, Zhou Q et al. (2015). Toxic and non-toxic strains of Microcystis aeruginosa induce temperature dependent allelopathy 
toward growth and photosynthesis of Chlorella vulgaris. Harmful Algae 48: 21-29.

Noctor G, Arisi ACM, Jouanin L, Foyer CH. (1998). Manipulation of glutathione and amino acid biosynthesis in the chloroplast. Plant Physiol 118: 471-482.

Paerl HW, Fulton RS, Moisander PH, Dyble J. (2001). Harmful freshwater algal blooms, with emphasis on cyanobacteria. Sci World J 1: 76-113.

Paerl HW, Paul VJ. (2012). Climate change: links to global expansion of harmful cyanobacteria. Water Res 46: 1349-1363.

Paerl HW. (2008). Nutrient and other environmental controls of harmful cyanobacterial blooms along the freshwater marine continuum. Adv Exp Med Biol 619: 216-237.

Paerl HW. (2009). Controlling eutrophication along the freshwater marine continuum: dual nutrient ( $\mathrm{N}$ and $\mathrm{P}$ ) reductions are essential. Estuar Coast 32: 593-601.

Paul C, Barofsky A, Vidoudez C, Pohnert G. (2009). Diatom exudates influence metabolism and cell growth of cocultured diatom species. Mar Ecol Prog Ser 389: 61-70.

Poulson-Ellestad KL, Jones CM, Roy J, Viant MR, Fernández FM, Kubanek J et al. (2014). Metabolomics and proteomics reveal impacts of chemically mediated competition on marine plankton. Proc Natl Acad Sci USA 111: 9009-9014.

Qian HF, Sheng GD, Liu WP, Lu YC, Liu ZH, Fu ZW. (2008). Inhibitory effects of atrazine on Chlorella vulgaris as assessed by real-time polymerase chain reaction. Environ Toxicol Chem 27: 182-187.

Qian HF, Sun ZQ, Sun LW, Jiang YF, Wei Y, Xie J et al. (2013). Phosphorus availability changes chromium toxicity in the freshwater alga Chlorella vulgaris. Chemosphere 93: 885-891.

Qian HF, Wang RQ, Hu HJ, Lu T, Chen XL, Ye HQ et al. (2011). Enantioselective phytotoxicity of the herbicide imazethapyr and its effect on rice physiology and gene transcription. Environ Sci Technol 45: 7036-7043.

Qian HF, Yu SQ, Sun ZQ, Xie XC, Liu WP, Fu ZW. (2010). Effects of copper sulfate, hydrogen peroxide and N-phenyl-2-naphthylamine on oxidative stress and the expression of genes involved photosynthesis and microcystin disposition in Microcystis aeruginosa. Aquat Toxicol 99: 405-412.

Rigosi A, Carey CC, Ibelings BW, Brookes JD. (2014). The interaction between climate warming and eutrophication to promote cyanobacteria is dependent on trophic state and varies among taxa. Limnol Oceanogr 59: 99-114.

Rigosi A, Hanson P, Hamilton DP, Hipsey M, Rusak JA, Bois J et al. (2015). Determining the probability of cyanobacterial blooms: the application of Bayesian networks in multiple lake systems. Ecol Appl 25: 186-199.

Rosenwasser S, Creveld SGV, Schatz D, Malitsky S, Tzfadia O, Aharoni A et al. (2014). Mapping the diatom redox-sensitive proteome provides insight into response to nitrogen stress in the marine environment. Proc Natl Acad Sci USA 111: 2740-2745.

Sukenik A, Eshkol R, Livne A, Hadas O. (2002). Inhibition of growth and photosynthesis of the dinoflagellate Peridinium gatunense by Microcystis sp. (cyanobacteria): a novel allelopathic mechanism. Limnol Oceanogr 47: 1656-1663.

Tan JF, Zhao HJ, Hong JP, Han YL, Li H, Zhao WC. (2008). Effects of exogenous nitric oxide on photosynthesis, antioxidant capacity and proline accumulation in Wheat seedlings subjected to osmotic stress. World $J$ Agric Sci 4: 207-313.

Uronen P, Kuuppo P, Legrand C, Tamminen T. (2007). Allelopathic effects of toxic haptophyte Prymnesium parvum lead to release of dissolved organic carbon and increase in bacterial biomass. Microb Ecol 54: 183-193.

Wang X, Sun M, Wang J, Yang L, Luo L, Li P et al. (2012). Microcystis genotype succession and related environmental factors in Lake Taihu during cyanobacterial blooms. Microb Ecol 64: 986-999.

Work VH, Radakovits R, Jinkerson RE, Meuser JE, Elliott LG, Vinyard DJ et al. (2010). Increased lipid accumulation in the Chlamydomonas reinhardtiista710 starchlessisoamylase mutant and increased carbohydrate synthesis in complemented strains. Eukaryot Cell 9: 1251-1261.

Wu JT, Chiang YR, Huang WY, Jane WN. (2006). Cytotoxic effects of free fatty acids on phytoplankton algae and cyanobacteria. Aquat Toxicol 80: 338-349.

Yordanova ZP, Iakimova ET, Cristescu SM, Harren FJ, Kapchina-Toteva VM, Woltering EJ. (2010). Involvement of ethylene and nitric oxide in cell death in mastoparan-treated unicellular alga Chlamydomonas reinhardtii. Cell Biol Int 34: 301-308.

Zhao C, Wang X, Wang X, Wu K, Li P, Chang $\mathrm{N}$ et al. (2015). Glucose-6-phosphate dehydrogenase and alternative oxidase are involved in the cross tolerance of highland barley to salt stress and UV-B radiation. J Plant Physiol 181: 83-95.

(1) (9) This work is licensed under a Creative Commons Attribution-NonCommercialShareAlike 4.0 International License. The images or other third party material in this article are included in the article's Creative Commons license, unless indicated otherwise in the credit line; if the material is not included under the Creative Commons license, users will need to obtain permission from the license holder to reproduce the material. To view a copy of this license, visit http://creativecommons.org/ licenses/by-nc-sa/4.0/

(C) The Author(s) 2017

Supplementary Information accompanies this paper on The ISME Journal website (http://www.nature.com/ismej) 